\title{
MORTALITY FROM CANCER OF THE CERVIX UTERI IN BRITISH COLUMBIA AND OTHER PARTS OF CANADA
}

\author{
BY \\ H. S. AHLUWAliA*, M.B., B.S., D.C.P., M.C. PATH. \\ Institute for Medical Research, Kuala Lumpur \\ AND \\ RICHARD DOLL, O.B.E., M.D., D.Sc., F.R.C.P., F.R.S. \\ Medical Research Council's Statistical Research Unit, University College Hospital Medical School
}

The belief that carcinoma-in-situ of the cervix uteri commonly develops into invasive cancer is based on a variety of evidence including:

(i) The similar appearance of the cells in the two lesions;

(ii) The observation that some patients in whom carcinoma-in-situ had been diagnosed by biopsy subsequently developed invasive cancer;

(iii) The fact that carcinoma-in-situ is more prevalent than invasive cancer and appears at a younger age.

The evidence is reviewed in detail by Knox (1966) who, however, pointed out that unless the whole lesion is removed it is impossible to be sure that some part of an apparently in-situ lesion is not already invasive, and that if the lesion is removed in its entirety progression of the lesion can no longer be observed. Moreover, the prevalence data for carcinoma-in-situ and invasive cancer of the cervix that are at present available could be accounted for if a large proportion of carcinomas-in-situ regress, and a large proportion of fatal cancers develop explosively without going through a prolonged in-situ stage. The prophylactic value of treating carcinomain-situ is, therefore, open to question and is likely to remain so unless it is demonstrated in practice.

Cytological screening of healthy women has been undertaken on a large scale in British Columbia for longer than in most other parts of the world, and the effect of such screening should be apparent before we can expect to see it in Britain. We have, therefore, examined the trends in mortality from cancer of the uterus in British Columbia since 1955 and compared them with the trends recorded in Ontario and the rest of Canada where screening

* In receipt of a travelling fellowship from the International Agency for Research on Cancer. programmes have been less intense. Mortality rates have been calculated for each year from 1955 to 1965 for three age groups (20 to 44 years, 45 to 64 years and 65 years and over). Within each broad age group the rates have been standardized for age, using rounded-off weights derived from Segi's selected world population (Doll, Payne, and Waterhouse, 1966). $†$ Table I and Figs $1 \mathrm{~A}$ and $1 \mathrm{~B}$ (overleaf) show the rates for cancer of the cervix and Table II and Fig. 2 (overleaf) show the rates for cancers of other parts of the uterus and uterus unspecified.

From Table $I$ it is evident that the mortality attributed to cancer of the cervix was closely similar in all parts of Canada over the last 5 years. At the beginning of the period the rates were somewhat higher in Ontario and the rest of Canada than in British Columbia, but the difference was eliminated with the passage of time. In British Columbia the mortality was practically the same in 1955-56 and in 1964-65 at ages 20 to 44 years and 65 years and over (3.9 and 4.3 per 100,000 and 22.7 and $23 \cdot 5$ per 100,000 respectively), and fell only at ages 45 to 64 years (from $20 \cdot 2$ to $16 \cdot 5$ per 100,000 ).

Table II shows that the rates for other cancers of the uterus were closely similar in British Columbia and Ontario, but were somewhat higher in the rest of Canada. In all parts of Canada there was a tendency for the rates to fall over the period, but the trend was not marked except at ages 20 to 44 years in British Columbia (where no deaths were recorded in the last 4 years).

The rates, it should be noted, are based on certified causes of death and they are unlikely to be completely accurate. In particular, some deaths due

+0.8 at ages $20-24$ and $25-29$ years; 0.6 at ages $30-34,35-39$ $40-44$, and $45-49$ years; 0.5 at ages $50-54$ years; 0.4 at ages $55-59$ and $60-64$ years; 0.3 at ages $65-69$ years; 0.2 at ages $70-74$ years; 0.1 at ages 75-79 years; and 0.05 at ages $80-84$ and 85 years and over. 
TABLE I

STANDARDIZED MORTALITY RATES FROM CANCER OF THE CERVIX UTERI* IN PARTS OF CANADA, 1955-65

\begin{tabular}{|c|c|c|c|c|c|c|c|c|c|c|c|c|c|}
\hline \multirow{2}{*}{$\begin{array}{c}\text { Age Group } \\
\text { (yrs) }\end{array}$} & \multirow{2}{*}{ Area } & \multicolumn{11}{|c|}{ Standardized Mortality per 100,000 Women (year) } & \multirow{2}{*}{$\begin{array}{l}\text { No. of } \\
\text { Deaths } \\
\text { in } 1965\end{array}$} \\
\hline & & 1955 & 1956 & 1957 & 1958 & 1959 & 1960 & 1961 & 1962 & 1963 & 1964 & 1965 & \\
\hline \multirow{3}{*}{$20-44$} & British Columbia & $4 \cdot 8$ & $3 \cdot 0$ & $2 \cdot 8$ & 6.0 & $6 \cdot 8$ & $4 \cdot 1$ & $6 \cdot 4$ & $4 \cdot 0$ & $4 \cdot 7$ & $3 \cdot 9$ & $4 \cdot 6$ & 15 \\
\hline & Ontario & $5 \cdot 3$ & $5 \cdot 8$ & $4 \cdot 9$ & $4 \cdot 8$ & $5 \cdot 7$ & $5 \cdot 0$ & $3 \cdot 7$ & $5 \cdot 4$ & $5 \cdot 3$ & $4 \cdot 3$ & $3 \cdot 4$ & 44 \\
\hline & Rest of Canada & $5 \cdot 1$ & $5 \cdot 6$ & $5 \cdot 5$ & $5 \cdot 6$ & $5 \cdot 9$ & $4 \cdot 8$ & $4 \cdot 2$ & $4 \cdot 5$ & $4 \cdot 0$ & $5 \cdot 0$ & $4 \cdot 4$ & 82 \\
\hline \multirow{3}{*}{$45-64$} & British Columbia & $19 \cdot 2$ & $21 \cdot 2$ & $17 \cdot 7$ & $20 \cdot 4$ & $18 \cdot 7$ & $16 \cdot 4$ & $18 \cdot 8$ & $22 \cdot 2$ & $20 \cdot 0$ & $19 \cdot 4$ & $13 \cdot 5$ & 23 \\
\hline & Ontario & $23 \cdot 5$ & $25 \cdot 4$ & $24 \cdot 1$ & $19 \cdot 8$ & $24 \cdot 3$ & $18 \cdot 9$ & $19 \cdot 0$ & $19 \cdot 7$ & $18 \cdot 9$ & $18 \cdot 2$ & $23 \cdot 1$ & 136 \\
\hline & Rest of Canada & $22 \cdot 5$ & $22 \cdot 4$ & $21 \cdot 5$ & $22 \cdot 2$ & 20.9 & $19 \cdot 5$ & $19 \cdot 1$ & $19 \cdot 7$ & $18 \cdot 6$ & $18 \cdot 0$ & $18 \cdot 1$ & 168 \\
\hline \multirow{3}{*}{65 and Over } & British Columbia & $23 \cdot 4$ & $22 \cdot 0$ & $24 \cdot 8$ & $19 \cdot 1$ & $16 \cdot 4$ & $12 \cdot 8$ & $30 \cdot 3$ & $59 \cdot 7$ & 20.9 & $25 \cdot 3$ & $21 \cdot 6$ & 18 \\
\hline & Ontario & $37 \cdot 3$ & $31 \cdot 3$ & $35 \cdot 5$ & $35 \cdot 4$ & $35 \cdot 8$ & $26 \cdot 0$ & 33.9 & $30 \cdot 3$ & $30 \cdot 4$ & $20 \cdot 4$ & $22 \cdot 8$ & 74 \\
\hline & Rest of Canada & $27 \cdot 7$ & $32 \cdot 7$ & $29 \cdot 1$ & $33 \cdot 3$ & 30.9 & $27 \cdot 6$ & $26 \cdot 5$ & $24 \cdot 1$ & $25 \cdot 2$ & $22 \cdot 9$ & $26 \cdot 2$ & 106 \\
\hline
\end{tabular}

* "International Classification of Disease", abridged list A52 (World Health Organization, 1957).

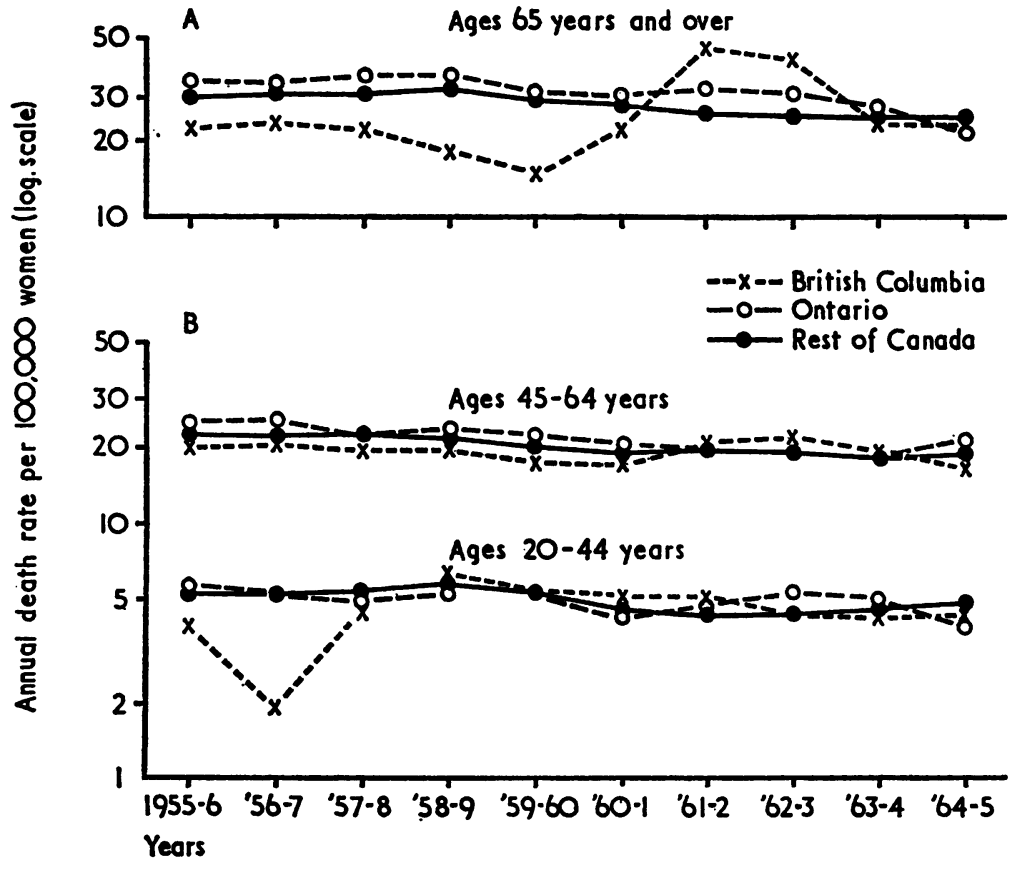

Fig. 1.-Average annual death rate from cancer of the cervix uteri in British Columbia, Ontario, and other parts of Canada from 1955-56 to 1964-65, standardized for age within broad age groups: $A$, ages 20 to 44 and 45 to 64 years; B, ages 65 years and over.

to cancer of the cervix may have been attributed to cancer of the uterus without further specification and so included with cancer of the corpus uteri in category A53 of the abridged list of causes of death (World Health Organization, 1957). It is, therefore, possible that a trend towards greater accuracy in certifying the cause of death may have obscured a reduction in mortality from cancer of the cervix by causing a number of deaths to be transferred from the unspecified group in category A53 to the category specific for cancer of the cervix (A52). If, however, both types of cancer are considered together, the downward trend in mortality in British Columbia is still not marked-and is less evident than in Ontario.

These data, therefore, do not provide evidence that mass cytological screening is able to reduce the 
TABLE II

STANDARDIZED MORTALITY RATES FROM CANCER OF THE CORPUS UTERI AND UTERUS UNDEFINED* IN PARTS OF CANADA, 1955-65

\begin{tabular}{|c|c|c|c|c|c|c|c|c|c|c|c|c|c|}
\hline \multirow{2}{*}{$\begin{array}{c}\text { Age Group } \\
\text { (yrs) }\end{array}$} & \multirow{2}{*}{ Area } & \multicolumn{11}{|c|}{ Standardized Mortality per 100,000 Women (year) } & \multirow{2}{*}{$\begin{array}{l}\text { No. of } \\
\text { Deaths } \\
\text { in } 1965\end{array}$} \\
\hline & & 1955 & 1956 & 1957 & 1958 & 1959 & 1960 & 1961 & 1962 & 1963 & 1964 & 1965 & \\
\hline \multirow{3}{*}{$20-44$} & British Columbia & $0 \cdot 7$ & 0.4 & $1 \cdot 4$ & $0 \cdot 7$ & $1 \cdot 9$ & $0 \cdot 3$ & $0 \cdot 3$ & $0 \cdot 0$ & $0 \cdot 0$ & $0 \cdot 0$ & $0 \cdot 0$ & $\mathbf{0}$ \\
\hline & Ontario & 0.5 & 0.4 & 0.9 & 0.7 & 0.9 & $0 \cdot 7$ & $0 \cdot 5$ & $0 \cdot 3$ & 0.4 & 0.6 & $0 \cdot 8$ & 9 \\
\hline & Rest of Canada & $1 \cdot 3$ & $2 \cdot 1$ & $1 \cdot 8$ & $1 \cdot 4$ & $1 \cdot 6$ & $1 \cdot 1$ & $1 \cdot 1$ & $2 \cdot 0$ & $1 \cdot 0$ & $1 \cdot 0$ & $1 \cdot 2$ & 23 \\
\hline \multirow{3}{*}{$45-64$} & British Columbia & $9 \cdot 5$ & $13 \cdot 4$ & $10 \cdot 4$ & $8 \cdot 9$ & $11 \cdot 8$ & $11 \cdot 0$ & $10 \cdot 7$ & $13 \cdot 1$ & $11 \cdot 5$ & $8 \cdot 5$ & $7 \cdot 5$ & 12 \\
\hline & Ontario & $12 \cdot 3$ & $10 \cdot 5$ & $11 \cdot 6$ & $22 \cdot 7$ & $12 \cdot 5$ & $10 \cdot 7$ & $9 \cdot 0$ & $10 \cdot 2$ & $9 \cdot 1$ & $8 \cdot 9$ & $8 \cdot 7$ & 54 \\
\hline & Rest of Canada & $15 \cdot 6$ & $19 \cdot 7$ & $18 \cdot 4$ & $15 \cdot 2$ & $16 \cdot 5$ & $15 \cdot 1$ & $15 \cdot 5$ & $15 \cdot 5$ & $16 \cdot 4$ & $13 \cdot 0$ & 10.9 & 98 \\
\hline \multirow{3}{*}{65 and Over } & British Columbia & $32 \cdot 1$ & $32 \cdot 8$ & $47 \cdot 5$ & $21 \cdot 0$ & $43 \cdot 1$ & $37 \cdot 4$ & $43 \cdot 5$ & $23 \cdot 8$ & $25 \cdot 6$ & $44 \cdot 5$ & $21 \cdot 1$ & 21 \\
\hline & Ontario & $19 \cdot 9$ & $35 \cdot 9$ & $36 \cdot 2$ & $57 \cdot 8$ & $43 \cdot 7$ & $26 \cdot 4$ & $28 \cdot 0$ & $40 \cdot 4$ & $34 \cdot 8$ & $31 \cdot 5$ & $28 \cdot 3$ & 87 \\
\hline & Rest of Canada & $57 \cdot 2$ & $38 \cdot 5$ & $49 \cdot 4$ & $43 \cdot 3$ & $43 \cdot 3$ & $48 \cdot 5$ & $46 \cdot 7$ & $44 \cdot 2$ & $46 \cdot 7$ & $46 \cdot 0$ & $37 \cdot 5$ & 153 \\
\hline
\end{tabular}

* "International Classification of Disease", abridged list A53 (World Health Organization, 1957).

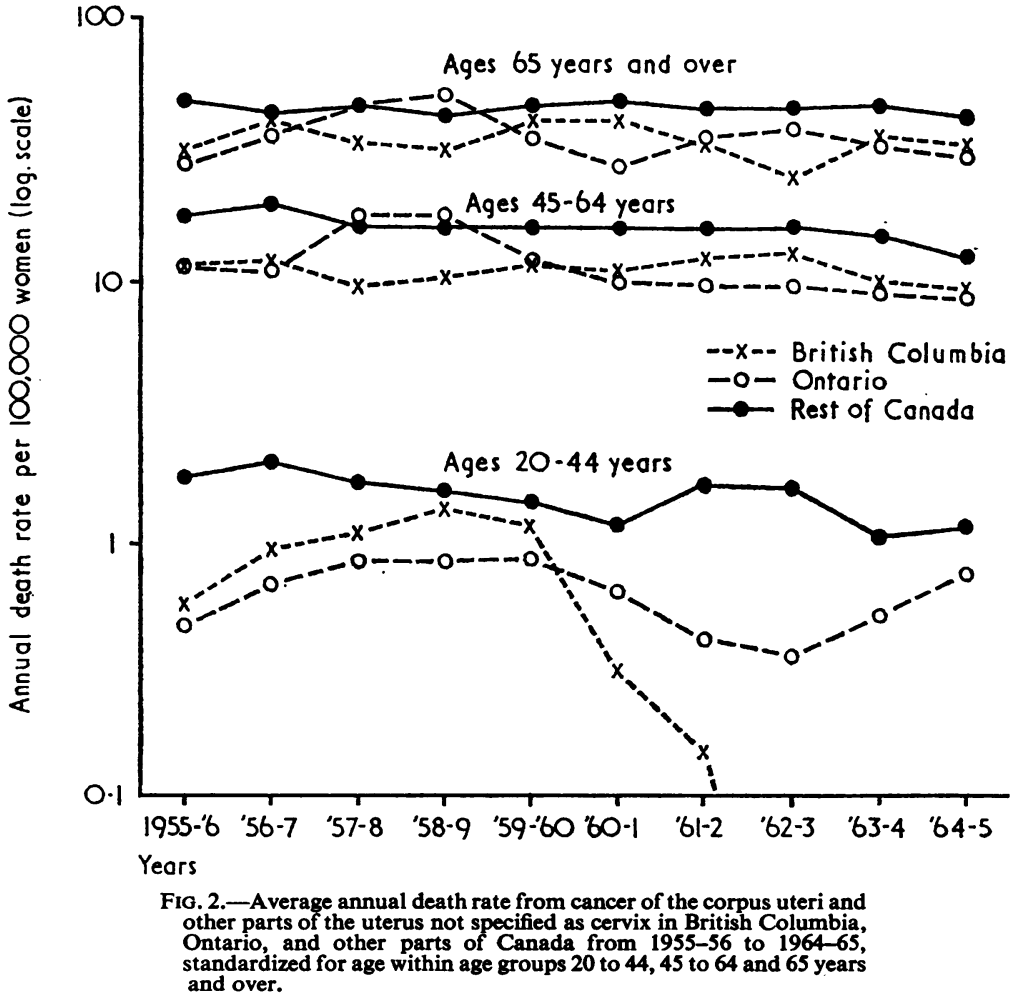

mortality from cancer of the uterus; but neither do they prove the contrary. Screening was started in British Columbia in 1949, and 6 years later more than 10,000 women were being examined each year. Subsequently the number rose to over 100,000 per year (Bryans, Boyes, and Fidler, 1964), and Worth, Boyes, and Fidler (1967) estimated that 24 per cent. of all women resident in British Columbia, who were over 20 years of age, had been examined at least once by the end of 1960 and 57 per cent. by the end of 1964 . Since approximately 90 per cent. of deaths from cancer of the cervix occur within 5 years of the diagnosis (Bailar, 1964), it might be anticipated that by 1965 the death rate would have been reduced by more than 20 per cent. This figure may, however, be too high. It fails to take into account two facts: 
(i) Some of the women who were screened will have already developed invasive cancer, and in these women screening can be expected to have improved the prognosis but hardly to have guaranteed a 100 per cent. cure.

(ii) The women who were examined were selfselected and it must be presumed that those who came forward for examination were less at risk than those who did not. The effect of self-selection is, however, likely to be less marked in Canada than in Britain (Worth, and others, 1967; Boyd, Gibbs, Labrum and Philps, 1967).

On present evidence it is not possible to estimate the quantitative effect of these factors. The effect of the first factor, however, should not last for more than a few years so that, if the death rate in British Columbia is not appreciably reduced in the next 2 to 3 years, it will be reasonable to conclude either that the treatment of carcinoma-in-situ is not effective in preventing death from cancer of the cervix, or that more than 50 per cent. of the population need to be screened before it is. Alternatively, if the death rate is reduced-and the reduction is greater than in other parts of Canada-this will provide good evidence of the prophylactic value of the screening programme.

\section{SUMMARY}

Trends in mortality from cancer of the cervix and other cancers of the uterus have been examined for the period 1955-65 in British Columbia, Ontario, and the rest of Canada. The mortality rates differ little between the different parts of Canada and there is no evidence of any greater reduction in mortality from cancer of the cervix in British Columbia than elsewhere.

If mass cytological screening is an effective method $\frac{3}{D}$ of preventing death from cancer of the cervix, a reduction in mortality in British Columbia should be seen in the next few years.

\section{REFERENCES}

Bailar, J. C. (1964). In "International Symposium on End Results of Cancer Therapy." National Cancer Institute Monograph 15, U.S. Public Health Service, Bethesda, Maryland, pp. 51-81 (Survival of patients with cancer of the uterine cervix and corpus).

Boyd, J. T., Gibbs, D. F., Labrum, A. H., and Philps, $\vec{\omega}$ F. R. (1967). Brit. med. J., 2, 785 (Cervical screening for carcinoma : a comparison of cytological and enzyme (6-phosphogluconate dehydrogenase) methods and clinical findings).

Bryans, F. E., Boyes, D. A., and Fidler, H. K. (1964). Amer. J. Obstet. Gynec., 88, 898 (The influence of a $\vec{\partial}$ cytological screening programme upon the incidence of $\underset{ }{2}$ invasive squamous cell carcinoma of the cervix in British Columbia).

Doll, R., Payne, P., and Waterhouse, J. (1966). "Cancer Incidence in Five Continents." Union Internationale contre le Cancer. Technical Report. Springer, Berlin.

Knox, E. G. (1966). In "Problems and Progress in $\vec{\theta}$ Medical Care", Second Series, ed. G. McLachlas (Nuffield Provincial Hospitals Trust) Oxford Universito Press, London, pp. 277-309 (Cervical cytology: scrutiny of the evidence).

World Health Organization (1957). "Manual of the International Statistical Classification of Diseases, Injuries and Causes of Death: Seventh Revision". World Health Organization, Geneva.

Worth, A. J., Boyes, D. A., and Fidler, H. K. (1967). J. Obstet. Gynaec. Brit. Cwlth, 74, 479 (The acceptance of the cervical cytology screening programme in the province of British Columbia). 